\title{
Lactobacillus fermentum promotes adipose tissue oxidative phosphorylation to protect against diet- induced obesity
}

Youngmin Yoon ${ }^{1}$, Gihyeon Kim', Myung-giun Noh', Jeong-hyeon Park², Mongjoo Jang ${ }^{2}$, Sungsoon Fang (1) ${ }^{3}$ and Hansoo Park ${ }^{1,2}$

\begin{abstract}
The gut microbiota has pivotal roles in metabolic homeostasis and modulation of the intestinal environment. Notably, the administration of Lactobacillus spp. ameliorates diet-induced obesity in humans and mice. However, the mechanisms through which Lactobacillus spp. control host metabolic homeostasis remain unclear. Accordingly, in this study, we evaluated the physiological roles of Lactobacillus fermentum in controlling metabolic homeostasis in dietinduced obesity. Our results demonstrated that L. fermentum-potentiated oxidative phosphorylation in adipose tissue, resulting in increased energy expenditure to protect against diet-induced obesity. Indeed, oral administration of $L$. fermentum LM1016 markedly ameliorated glucose clearance and fatty liver in high-fat diet-fed mice. Moreover, administration of L. fermentum LM1016 markedly decreased inflammation and increased oxidative phosphorylation in gonadal white adipose tissue, as demonstrated by transcriptome analysis. Finally, metabolome analysis showed that metabolites derived from L. fermentum LM1016-attenuated adipocyte differentiation and inflammation in 3T3-L1 preadipocytes. These pronounced metabolic improvements suggested that the application of L. fermentum LM1016 could have clinical applications for the treatment of metabolic syndromes, such as diet-induced obesity.
\end{abstract}

\section{Introduction}

Obesity is defined as abnormal or excessive fat accumulation. Approximately $30 \%$ of the world's population is considered obese or overweight, and the global prevalence of obesity continues to rise ${ }^{1,2}$. Fat accumulation in the visceral adipose tissue and liver has been shown to increase the secretion of proinflammatory cytokines, such as tumor necrosis factor (TNF)- $\alpha$, interleukin (IL)-1, IL-6, and leptin, leading to metabolic tissue inflammation and insulin resistance in obese individuals ${ }^{3-5}$. Thus, obesity is a major risk factor for metabolic diseases, such as type 2

Correspondence: Sungsoon Fang (sfang@yuhs.ac) or

Hansoo Park (hspark27@gist.ac.kr)

'Department of Biomedical Science and Engineering, Gwangju Institute of Science and Technology (GIST), Gwangju, Korea

${ }^{2}$ Genome and Company, Pangyo-ro 255, Bundang-gu, Seoungnam, Korea

Full list of author information is available at the end of the article

These authors contributed equally: Youngmin Yoon, Gihyeon Kim diabetes, nonalcoholic fatty liver disease, and cardiovascular disease ${ }^{4,6,7}$.

The gut microbiome has been shown to have essential roles in the synthesis of essential amino acids and vitamins, elimination of toxic compounds, and regulation of the immune system ${ }^{8-11}$. The composition of the gut microbiome is affected by various factors, such as genetics, geographical location, and age $\mathrm{e}^{12,13}$, and dysbiosis or imbalance of the gut microbiome composition is correlated with inflammatory bowel diseases, cancer, neurological disorders, and metabolic diseases ${ }^{14-16}$. Obesity-related alterations in the gut microbiome composition are characterized by changes in the Firmicutes to Bacteroidetes ratio, which is increased in obese humans and mice ${ }^{17,18}$. Recently, several studies have reported that the administration of Lactobacillus spp. ameliorates diet-induced body weight gain and fat accumulation and decreases the levels of serum 
metabolic biomarkers, such as blood glucose, insulin, and triglycerides ${ }^{19-22}$. However, the underlying mechanisms through which Lactobacillus spp. ameliorated diet-induced obesity remain unclear.

Accordingly, in this study, we evaluated the protective effects of Lactobacillus fermentum LM1016 against dietinduced obesity. Our results provide important insights into the potential applications of L. fermentum LM1016 administration for the treatment of metabolic disorders, including obesity.

\section{Research design and methods Mouse models}

Animal procedures were approved by the Institutional Animal Care and Use Committee of CHA University. Male C57BL/6N mice (6 weeks old) were obtained from Orient Bio (Gapyeong, Gyeonggi, Korea). One week after adaptation, the mice were fed a normal diet (ND; 2018; Envigo, Indianapolis, IN, USA) with phosphate-buffered saline (PBS), a high-fat diet (HFD; 60\% of calories from fat; D12492; Research Diets, New Brunswick, NJ, USA) with PBS, or a HFD with probiotics. Body weights were measured once a week. After 8 weeks, mice were sacrificed in a $\mathrm{CO}_{2}$ chamber. Blood was collected by cardiac puncture after $\mathrm{CO}_{2}$ sacrifice. Liver and adipose tissues (gonadal fat, inguinal fat, and brown adipose tissue) were dissected precisely and weighed.

\section{Bacterial administration}

L. fermentum LM1016 was obtained from Lactomason (South Korea). L. acidophilus Rosell418 was obtained from Lallemand (Canada). L. acidophilus La14, L. salvarius Lrs-33, L. rhamnosus HOWARU Rhamnosus, and L. paracasei LPC37 were obtained from DuPont (USA). $L$. helveticus LH166 was obtained from Culture System Inc. (USA). Each Lactobacillus strain was resuspended in PBS, and mice were orally administered $1 \times 10^{9} \mathrm{CFU}$ of bacteria once a day for 8 weeks.

\section{Colonization of Lactobacillus fermentum LM1016}

For colonization experiments, mice were orally administered $1 \times 10^{9} \mathrm{CFU}$ of bacteria once, and stool samples were collected $4,8,12$, and $24 \mathrm{~h}$ after administration. DNA extractions were performed on $500 \mathrm{mg}$ of feces per sample using the FastDNA SPIN Kit for Soil (MP Biomedicals, Solon, CA, USA). L. fermentum LM1016 abundance was determined using a quantitative real-time PCR (qPCR) assay with L. fermentum-specific primers ${ }^{23}$ and normalized to $16 \mathrm{~S}$ rRNA-specific primers ${ }^{24}$. TaqMan $^{\mathrm{TM}}$ Fast Advanced Master Mix (Applied Biosystems, Foster City, CA, USA) and the StepOnePlus real-time PCR system (Applied Biosystems) were used for qPCR experiments. The primer sequences are listed in Supplementary Table 1.

\section{Tissue histology}

Liver, brown adipose tissue (BAT), and gonadal white adipose tissue (gWAT) were fixed in $4 \%$ paraformaldehyde for $24 \mathrm{~h}$. The tissues were then sequentially dehydrated in increasing concentrations of ethanol (50-100\%). Dehydrated tissue was infiltrated with $100 \%$ xylene, embedded in paraffin, and sectioned $(4 \mu \mathrm{m})$. Hematoxylin and eosin (H\&E) staining was performed according to standard methods.

\section{Liver triglyceride levels}

Liver extracts were prepared and incubated in a buffer containing $5 \% \mathrm{NP}-40 / \mathrm{ddH}_{2} \mathrm{O}$ solution, and supernatants containing triglycerides were separated. Triglyceride concentrations were measured on the supernatant fraction via a commercial colorimetric assay kit according to the manufacturer's recommendations (Abcam, Paris, France).

\section{RNA isolation and real-time polymerase chain reaction (PCR)}

Total RNA was extracted using TRIzol reagent according to the manufacturer's instructions. The purity and concentration of total RNA were determined using a NanoDrop One Spectrophotometer (Thermo Fisher). Briefly, $1 \mu \mathrm{g}$ of total RNA was reverse transcribed using a PrimeScript 1st strand cDNA synthesis kit (TaKaRa, Japan). Real-time PCR was performed using a CFX384 Touch real-time PCR System (Bio-Rad, Hercules, CA, USA) with SYBR Premix Ex Taq (TaKaRa) and genespecific primers. The thermal cycling conditions were as follows: $95^{\circ} \mathrm{C}$ for $10 \mathrm{~min}$, followed by 35 cycles of $95^{\circ} \mathrm{C}$ for $10 \mathrm{~s}, 60^{\circ} \mathrm{C}$ for $15 \mathrm{~s}$, and $72^{\circ} \mathrm{C}$ for $15 \mathrm{~s}$. The comparative threshold cycle (CT) was used to analyze the relative changes in gene expression normalized to $36 B 4 \mathrm{mRNA}$ expression.

\section{Biochemical analysis of mouse serum}

Serum insulin levels were measured in a 96-well microplate using a commercial Morinaga Ultra Sensitive Mouse/Rat Insulin ELISA Kit (MIoBS, Japan). The absorbance of each well was determined at $450 \mathrm{~nm}$ with a microplate reader (Molecular Device, CA, USA). Serum leptin levels were measured in a 96-well microplate using a commercial Morinaga Mouse/Rat Leptin ELISA Kit (MIoBS), with absorbance measurements at $450 \mathrm{~nm}$. Serum total cholesterol levels were measured using an automated apparatus (Mindray BS-200; Shenzhen, China). Serum bile acid levels were measured using a spectrophotometric enzymatic assay (Sigma Diagnostics, Inc., St. Louis, MO, USA) according to the manufacturer's instructions. Serum C-reactive protein (CRP) levels were measured using a mouse C-Reactive Protein/CRP Quantikine ELISA kit (R\&D system, Minneapolis, MN) 
according to the manufacturer's instructions. Glucose tolerance tests (GTTs) were performed after $12 \mathrm{~h}$ of fasting. Mice were injected with $2 \mathrm{~g}$ glucose per $\mathrm{kg}$ body weight intraperitoneally, and glucose concentrations were measured at $0,15,30,60$, and 120 min after injection.

\section{Transcriptome sequencing and gene set enrichment analysis (GSEA)}

RNA extraction from mouse intestines was performed using an RNeasy Mini Kit (Qiagen, Valencia, CA, USA). The 101-bp paired-end libraries were constructed with a TruSeq RNA Sample Prep Kit v2 (Illumina, San Diego, CA, USA) using $1 \mu \mathrm{g}$ of RNA. Whole-transcriptome sequencing (WTS) was performed on an Illumina HiSeq 2500 instrument. RNA-seq reads from each WTS experiment were aligned to the mouse reference genome (GRCm38) using STAR aligner ${ }^{25}$. Gene expression levels were quantified using RSEM ${ }^{26}$. To identify gene sets enriched in samples showing synergistic effects compared with samples without synergistic effects, GSEA was performed using javaGSEA desktop application (GSEA v2.1.0 $)^{27,28}$. Gene sets from gene ontology (GO) biological processes were used, and gene sets containing fewer than 15 genes and more than 500 genes were excluded. The $p$ values were calculated by permuting the data 1000 times for finding enriched gene sets. The GSEA software produced an enrichment score (ES), normalized ES, nominal $p$-value, and false discovery rate ( $Q$-value). Gene sets that were up- or downregulated with a $Q$-value of less than 0.25 were considered significant.

\section{Metabolomics profiling of mouse plasma, MRS medium, and bacterial supernatants}

Ultra-performance liquid chromatography/quadrupole timeof-flight mass spectrometry (UPLC-Q-TOF/MS) analysis

Four volumes of $80 \%$ methanol in water were added to $20 \mu \mathrm{L}$ of mouse plasma, bacterial culture supernatants, or MRS media. After vortexing for $1 \mathrm{~h}$ at room temperature, the mixtures were centrifuged at $13,000 \times g$ for $20 \mathrm{~min}$ at $4^{\circ} \mathrm{C}$. The supernatants were transferred to sample vials and analyzed by UPLC-Q-TOF/MS (Synapt G2Si; Waters, USA). UPLC separation was performed using an Acquity UPLC BEH C18 column $(2.1 \mathrm{~mm} \times 100 \mathrm{~mm}, 1.7 \mu \mathrm{m}$; Waters). Mobile phase A consisted of $0.1 \%$ formic acid in the water, whereas mobile phase B contained $0.1 \%$ formic acid acetonitrile. Samples were eluted using the following conditions: $0 \% \mathrm{~B}$ increased to $5 \% \mathrm{~B}$ at $1 \mathrm{~min}$, increased to $95 \% \mathrm{~B}$ at $9.0 \mathrm{~min}$, increased to $100 \% \mathrm{~B}$ at $10.5 \mathrm{~min}$, decreased to $0 \% \mathrm{~B}$ at $11 \mathrm{~min}$, and equilibrated for an additional $1.5 \mathrm{~min}$. The flow rate was $0.4 \mathrm{~mL} / \mathrm{min}$. The column temperature was maintained at $40^{\circ} \mathrm{C}$. The mass acquisition was performed in both positive (ESI+) and negative (ESI-) electrospray ionization modes with the following parameters: capillary voltage of $2.0 \mathrm{kV}$; cone voltage of $10 \mathrm{~V}$; source temperature of $110^{\circ} \mathrm{C}$; desolvation temperature of $400^{\circ} \mathrm{C}$; and desolvation gas flow of $650 \mathrm{~L} /$ h. Mass data were collected in the range of $\mathrm{m} / \mathrm{z} 60-1400$ with a scan time of $0.25 \mathrm{~s}$ and an interscan time of $0.02 \mathrm{~s}$ for $12 \mathrm{~min}$. Mass data, including the retention time, $\mathrm{m} / \mathrm{z}$, and ion intensities, were extracted using Progenesis QI software (Waters).

For metabolite identification, the following resources were used: exact mass, molecular formula suggested by the MassLynx software (Waters) based on the element composition and isotope composition of the parent mass ion; MS/MS spectra of the compounds; and metabolome databases, including the Human Metabolomics Database (http://www.hmdb.ca/), METLIN (http://metlin.scripps. edu/), MASS Bank (http://www.massbank.jp/), and LIPID MAPS (http://www.lipidmaps.org/).

\section{Bacterial transcriptome sequencing and annotation}

Bacterial RNA was extracted using a ZymoBIOMICS RNA Miniprep Kit (Zymo Research). Sequencing and library construction were performed on an Illumina HiSeq 2500 with 101-bp paired-ends. Ribosomal RNA was removed using a Ribo-Zero rRNA Removal Kit (Bacteria) (Epicentre). Libraries were prepared with a TruSeq RNA Sample Prep kit v2 (Illumina). RNAsequenced reads were mapped to the $L$. fermentum genome (NCBI, NC010610.1) using STAR with alignIntron MAX $1^{25}$. Then, the mapped reads were used to calculate read counts of genes using cufflinks ${ }^{29}$, and the gene list was input into the Cytoscape plug-in ClueGO v2.5.4 $4^{30}$ to annotate functionally grouped networks. Functionally related GO terms for biological processes in Escherichia coli (version: 18 November 2016) were grouped based on a kappa score greater than 0.4 with a network specificity of 4-10. Statistical significance was calculated using twosided hypergeometric tests, and the false discovery rate was corrected using the Bonferroni step down method.

\section{Preparation of bacterial extract}

L. fermentum LM1016 was harvested in MRS media and washed twice with PBS. L. fermentum LM1016 cells $(1 \times$ $10^{9} \mathrm{CFU} / \mathrm{mL}$ ) were lysed using FastPrep-24 $5 \mathrm{G}$ (MP Biomedicals, USA) and centrifuged at $15,000 \mathrm{rpm}$ for $5 \mathrm{~min}$. The supernatants were used after filtration with a $0.2-\mu \mathrm{m}$ filter.

\section{Differentiation of 3T3-L1 preadipocytes and cell culture}

3T3-L1 preadipocytes were cultured in vitro in Dulbecco's modified Eagle's medium (DMEM high glucose; Gibco) containing $10 \%$ bovine calf serum (Gibco) and 1\% penicillin/streptomycin (Gibco) in an atmosphere of $95 \%$ humidified air/5\% $\mathrm{CO}_{2}$. Cells were passaged prior to reaching confluence. Next, cells were seeded at a density of $4 \times 10^{5}$ cells/well in a 6 -well plate and allowed to reach 
$100 \%$ confluence (day 0). The basal medium was then replaced with DMEM high glucose containing $10 \%$ fetal bovine serum (FBS; Gibco), 1\% penicillin/streptomycin, $0.5 \mathrm{mM}$ IBMX, $1 \mu \mathrm{M}$ dexamethasone, and $10 \mu \mathrm{g} / \mathrm{mL}$ insulin solution. On day 2, the medium was changed to DMEM containing $10 \% \mathrm{FBS}, 1 \%$ penicillin/streptomycin, and $1 \%$ bacterial extract or $10 \mu \mathrm{g} / \mathrm{mL}$ linoleic acid (Merck, Germany). The media were changed every 2 days. On day 10, 3T3-L1 adipocyte differentiation was observed by Oil Red O staining. RAW 264.7 macrophage cells were obtained from the Korean Cell Line Bank (Seoul, Korean) and cultured in DMEM containing 10\% bovine calf serum (Gibco) and $1 \%$ penicillin/streptomycin (Gibco) at $37{ }^{\circ} \mathrm{C}$ in an atmosphere of $95 \%$ humidified air $/ 5 \% \mathrm{CO}_{2}$.

\section{Oil Red $O$ staining}

3T3-L1 cells were washed with PBS twice, fixed with $10 \%$ formalin at room temperature for $10 \mathrm{~min}$, and stained with Oil Red O (Sigma) at $37^{\circ} \mathrm{C}$ for $10 \mathrm{~min}$.

\section{Protein levels of IL- 6 and TNF- $a$ in the culture medium}

Cells were treated with $100 \mathrm{ng} / \mathrm{mL}$ lipopolysaccharide (LPS; Sigma-Aldrich) with or without $1 \%$ bacterial extraction medium for $24 \mathrm{~h}$. IL- 6 and TNF- $\alpha$ concentrations were measured using ELISA kits.

\section{Statistical analysis}

In vivo and in vitro data were analyzed using Prism 4.0 (GraphPad). Body weights and GTTs were evaluated by two-way analysis of variance (ANOVA). Statistical analysis of different groups was performed using Student's $t$ test or one-way ANOVA.

\section{Results}

Administration of $L$. fermentum reduced diet-induced body weight gain

To identify the strains of Lactobacillus spp. that protect against diet-induced obesity, we tested seven Lactobacillus strains (Supplementary Table S2) in HFD-fed mice (Fig. 1a). Although HFD-fed mice showed significant increases in body weight gain compared with ND-fed controls, we found that administration of L. fermentum LM1016 significantly reduced diet-induced body weight gain (Fig. 1b). Surprisingly, the administration of other strains of Lactobacillus did not have anti-obesity effects in HFD-fed mice (Fig. 1b). To examine the molecular mechanisms mediating the anti-obesity effects of $L$. fermentum LM1016, we performed WTS of L. fermentum LM1016. Several metabolic pathways, including the oxidoreduction coenzyme metabolic process, pyridinecontaining compound metabolic process, nicotinamide nucleotide metabolic process, and pyridine nucleotide metabolic process, were identified as functionally grouped networks of $L$. fermentum LM1016 GO categories (Fig. 1c). The balance of oxidative stress and oxidoreduction has been shown to have crucial roles in the pathogenesis of metabolic syndromes, such as cardiovascular diseases, insulin resistance, and metabolic disorders ${ }^{31-34}$. Therefore, the functional gene network of the oxidoreduction coenzyme metabolic process was one of the key molecular mechanisms mediating the anti-obesity effects of $L$. fermentum LM1016. To determine whether L. fermentum LM1016 colonized the host intestinal tract after oral administration, we next harvested fecal samples at different time points after administration of $L$. fermentum LM1016. We observed that $L$. fermentum was localized for several hours after oral administration (Supplementary Fig. S1). However, L. fermentum was not detected in the fecal samples $24 \mathrm{~h}$ after oral administration, implying that L. fermentum transiently localized in the host intestinal tract (Supplementary Fig. S1). These data clearly suggest that daily treatment of L. fermentum LM1016 is required to modulate host metabolic homeostasis.

\section{Administration of $L$. fermentum-stimulated brown adipocyte function by increasing bile acid signaling}

Because L. fermentum LM1016 treatment markedly reduced body weight gain in HFD-fed mice, we next examined the cellular functions of BAT, including thermogenesis. BAT has important roles in both basal and adaptive energy metabolism by nonshivering thermogenesis and promotes energy expenditure to improve insulin sensitivity and reduce body weight gain ${ }^{35-37}$. Histological analysis revealed that lipid droplet sizes in BAT were reduced in L. fermentum LM1016-treated mice compared with vehicle-treated mice (Fig. 2a). With gene expression profiling analysis, we observed that the expression levels of genes involved in thermogenesis, including Ucp1, Dio2, Acadm, Esrr, and Aox, were significantly increased in BAT from $L$. fermentum LM1016-treated mice, suggesting that BAT-mediated energy expenditure was stimulated by administration of L. fermentum LM1016 (Fig. 2b).

Previous reports have shown that bile acids bind to the G protein-coupled receptor TGR5 to potentiate thyroid hormone signaling in BAT, leading to increased energy expenditure and reduced body weight gain $^{38}$. We next determined whether administration of $L$. fermentum LM1016 increased bile acid signaling to potentiate BATmediated energy expenditure. Notably, serum bile acid levels were significantly elevated in $L$. fermentum LM1016-treated mice compared with vehicle-treated HFD mice (Fig. 2c). Bile acids are synthesized from cholesterol in hepatocytes by various liver enzymes, including cholesterol $7 \alpha$-hydroxylase (CYP7A1), sterol 12 $\alpha$-hydroxylase, and sterol-27-hydroxylase (CYP27A1) ${ }^{39}$. Therefore, we next examined the expression levels of these 

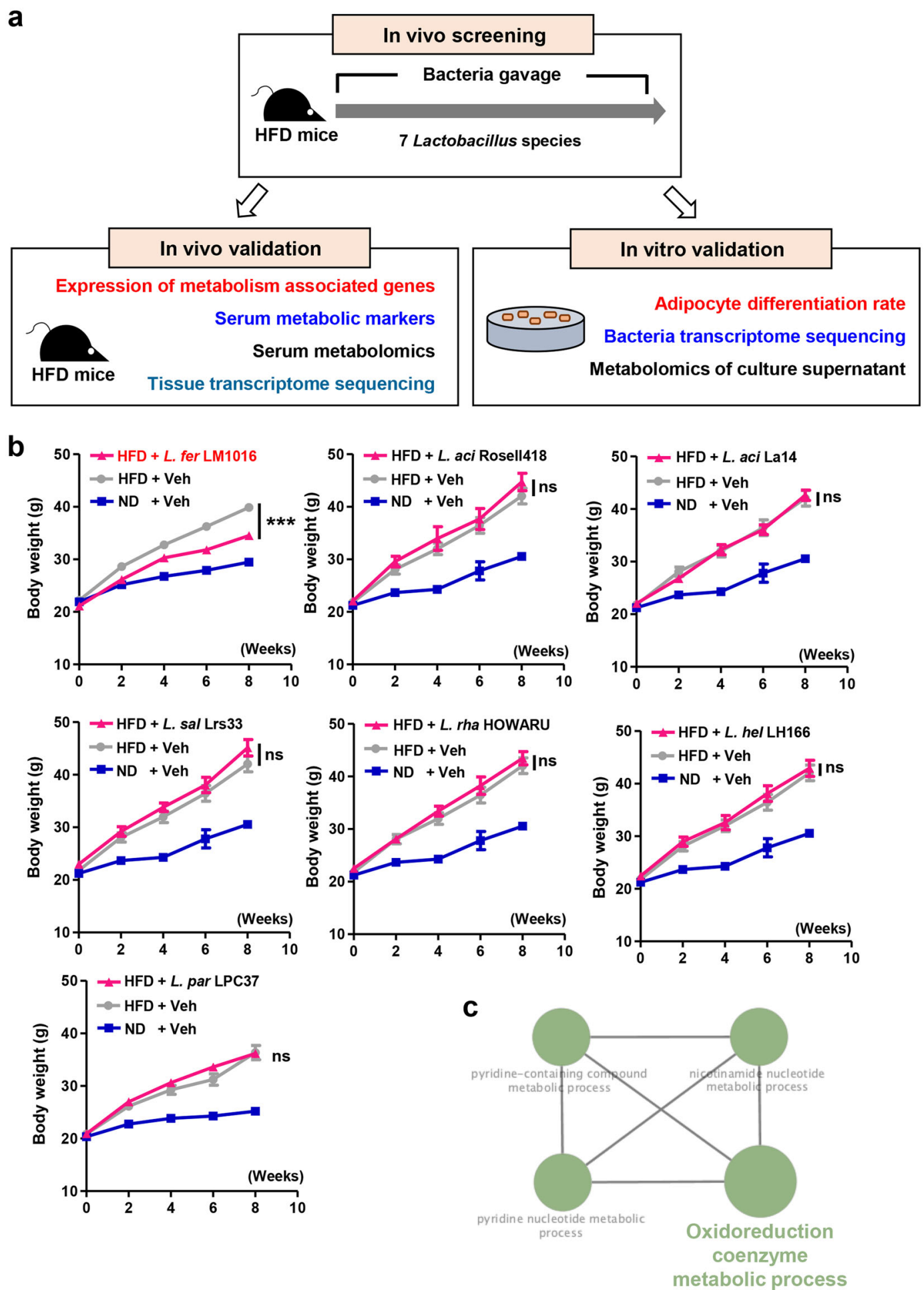

Fig. 1 Administration of $L$. fermentum LM1016 reduced diet-induced obesity. a Schematic representation of the in vivo and in vitro experiments. b Body weight curves in normal diet (ND)- and high-fat diet (HFD)-fed mice and HFD-fed mice treated with Lactobacillus strains. c The ClueGO functionally grouped network of L. fermentum LM1016. ns not significant, ${ }^{* * *} p<0.001$, as determined by two-way ANOVA (b). Data are expressed as means \pm SEMs. 
a

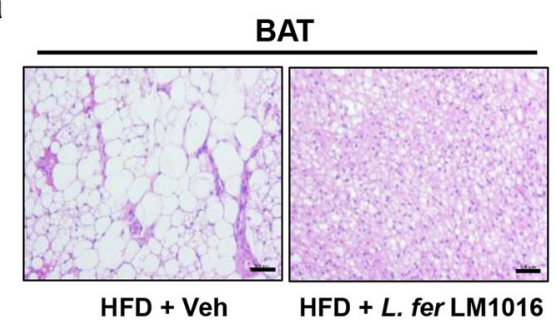

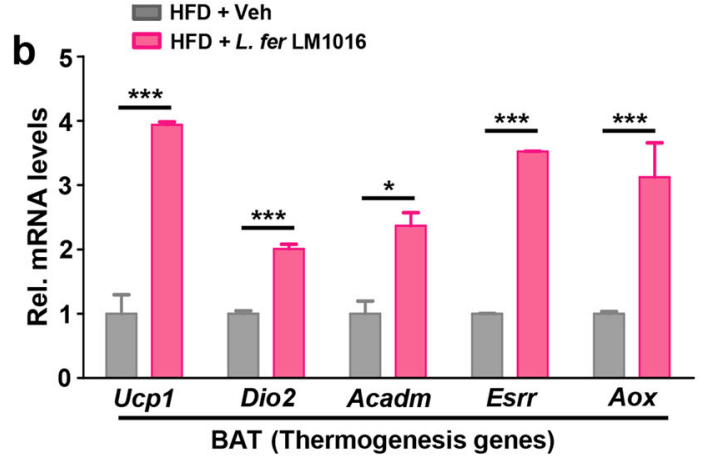

C
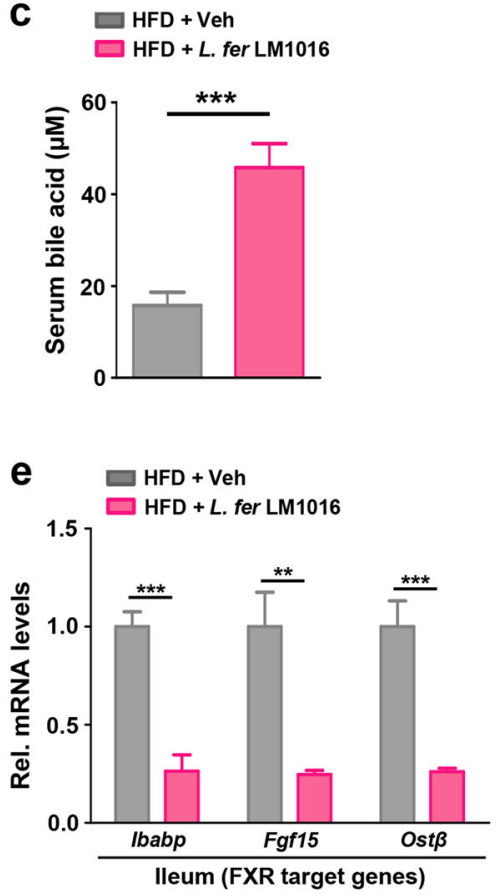

d $\square$ HFD + Veh $\square$ HFD + L. fer LM1016
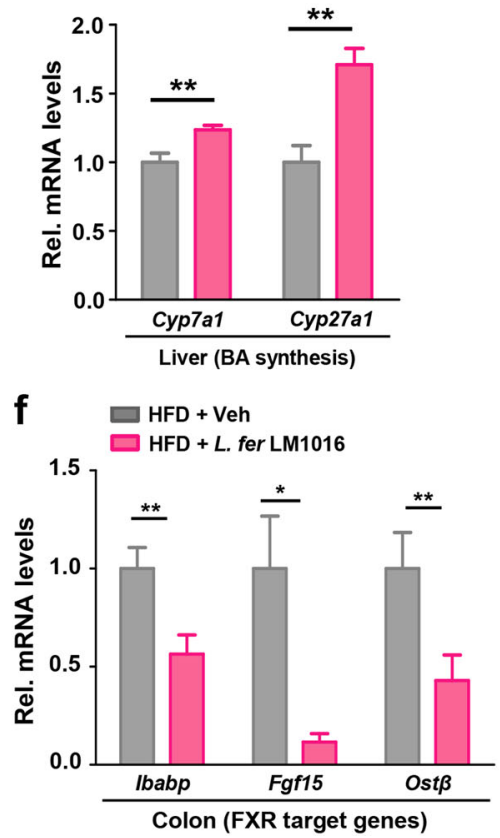

Fig. 2 Administration of $L$. fermentum- stimulated brown adipocyte function by increasing serum levels of bile acids. a Hematoxylin-eosin (H\&E) staining of brown adipose tissue (BAT). Scale bar, $100 \mu \mathrm{m}$. $\mathbf{b}$ mRNA expression of thermogenesis genes in BAT. c Serum bile acid levels. $\mathbf{d}$ mRNA expression of bile acid (BA) synthesis genes in the liver. e mRNA expression of FXR target genes in the ileum. $\mathbf{f}$ mRNA expression of FXR target genes in the colon. ${ }^{*} p<0.05,{ }^{* *} p<0.01,{ }^{* * *} p<0.001$, as determined by Student's $t$-test $(\mathbf{b}-\mathbf{f}$ ). Data are expressed as means \pm SEMs.

genes in the liver. The expression of bile acid synthesis genes (i.e., CYP7A1 and CYP27A1) was significantly upregulated in the livers of L. fermentum LM1016-treated mice compared with that in HFD mice, implying that $L$. fermentum LM1016 treatment increased hepatic bile acid synthesis (Fig. 2d). Previously, intestinal fibroblast growth factor 15 (FGF15) was shown to suppress hepatic bile acid synthesis by blocking CYP7A1 expression in mice ${ }^{40}$. In this study, we observed that L. fermentum LM1016 treatment markedly suppressed FGF15 gene expression in the ileum and colon (Fig. 2e, f), suggesting that L. fermentum LM1016 treatment may modulate intestinal signaling to increase hepatic bile acid synthesis to stimulate BAT-mediated energy expenditure.

\section{Administration of $L$. fermentum improved serum metabolic} parameters

Given that obesity is closely related to type 2 diabetes mellitus and metabolic disorders, we next examined whether administration of L. fermentum LM1016 improved serum metabolic biomarkers in diet-induced obese mice. GTT analysis revealed that fasting blood glucose levels were markedly reduced in L. fermentum LM1016-treated mice compared with vehicle-treated HFD-fed mice (Fig. 3a). While blood glucose levels were highly elevated after glucose injection in vehicle-treated HFD-fed mice, L. fermentum LM1016 treatment potentiated glucose clearance to reduce blood glucose levels (Fig. 3a). Consistent with the improvement in glucose 

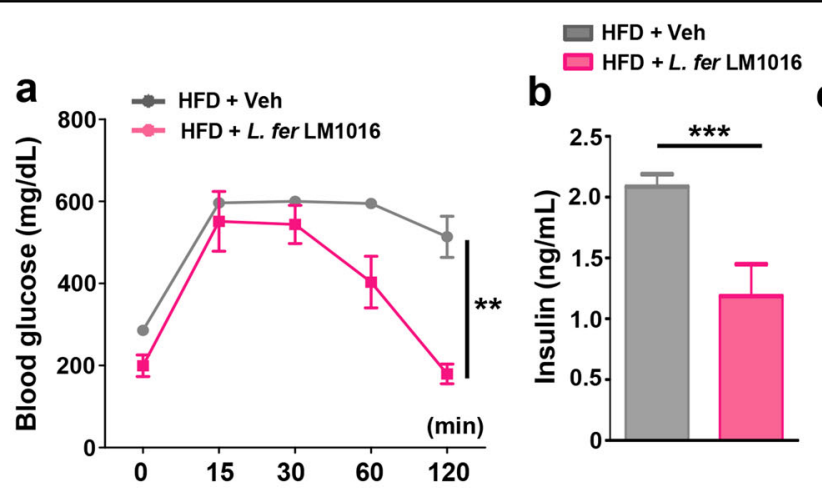

b

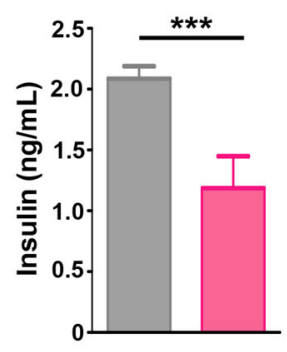

C
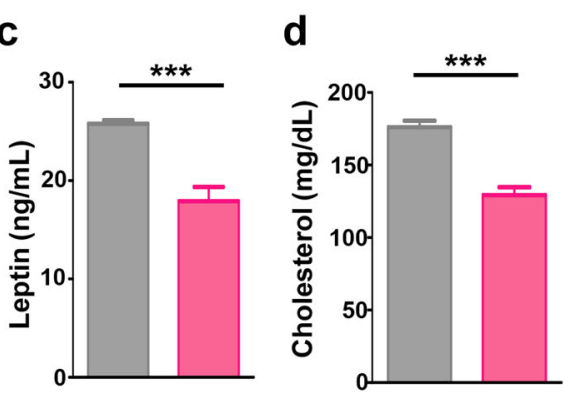

e
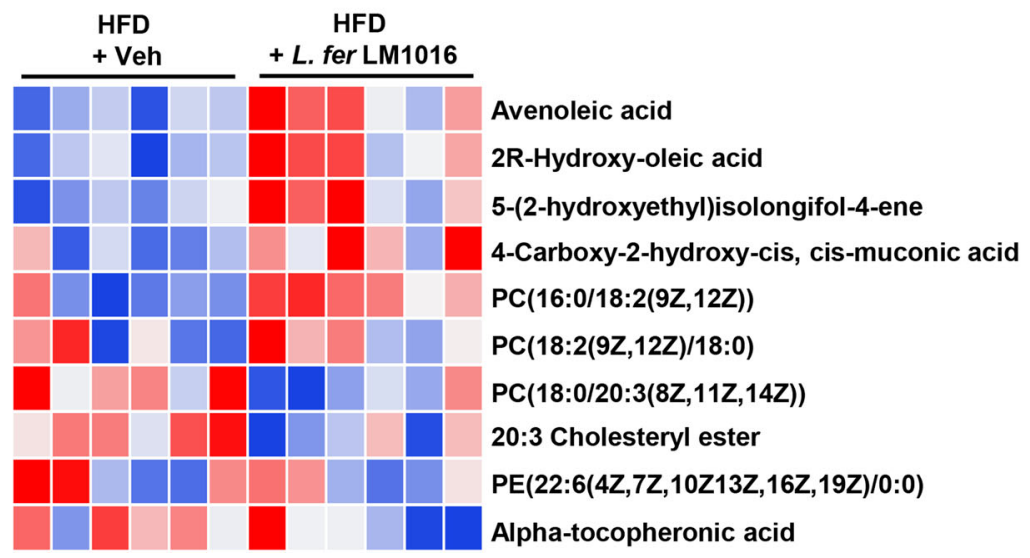

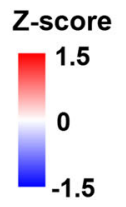

Fig. 3 Administration of L. fermentum improved serum metabolic parameters. a Glucose tolerance test of HFD-fed mice treated with vehicle or L. fermentum LM1016. b Serum insulin levels. c Serum leptin levels. d Serum cholesterol levels. e Heatmap of differentially detected serum metabolites between high-fat diet (HFD)-fed mice and HFD-fed mice treated with L. fermentum LM1016. ${ }^{* *} p<0.01$, ${ }^{* * *} p<0.001$, as determined by two-way ANOVA (a) and Student's t-test (b-d). Data are expressed as means \pm SEMs.

clearance, we also observed that fasting serum insulin levels were markedly decreased by L. fermentum LM1016 treatment (Fig. 3b). Notably, blood levels of leptin and cholesterol were also significantly reduced in L. fermentum LM1016-treated mice (Fig. 3c, d).

The gut microbiome has been shown to produce diverse serum metabolites that regulate both metabolic homeostasis and immunity ${ }^{41}$. To explore the correlations between serum metabolites and L. fermentum LM1016 administration, we analyzed serum metabolomic profiling of vehicle-treated and L. fermentum LM1016-treated HFD-fed mice. We observed that several metabolites, including avenoleic acid, 2R-hydroxy-oleic acid, and PC (16:0/18:2(9Z,12Z)), were markedly increased by $L$. fermentum LM1016 administration (Fig. 3e). In prior studies, serum cholesteryl ester has been reported to reflect adiposity and to be associated with the insulin sensitivity index ${ }^{42}$. Similarly, in this study, we also observed that serum levels of 20:3 cholesteryl ester were markedly reduced in mice administered $L$. fermentum LM1016. Thus, the metabolomic analysis revealed that administration of L. fermentum LM1016 altered serum metabolites, resulting in modulation of metabolic homeostasis to reduce adiposity.

\section{Administration of $L$. fermentum reduced hepatic gluconeogenesis and lipogenesis to ameliorate hepatic steatosis}

We next examined the wet weights of livers from HFDfed mice treated with vehicle or L. fermentum LM1016. We observed that liver weights were markedly reduced in HFD-fed mice treated with $L$. fermentum LM1016 (Fig. 4a). Hepatic steatosis, a well-known complication of obesity, is a condition of triglyceride accumulation in hepatocytes and can lead to hepatocyte injury, cell death, and fibrosis ${ }^{43,44}$. Administration of L. fermentum LM1016 led to a significant reduction in lipid droplet size and triglyceride accumulation in the liver (Fig. 4b, c). To investigate the molecular mechanisms of how L. fermentum LM1016-attenuated hepatic steatosis, we performed quantitative real-time PCR (qPCR) to confirm the expression of hepatic steatosis-associated genes. Hepatic genes associated with gluconeogenesis, lipogenesis, and lipid sequestration were markedly decreased in mice 

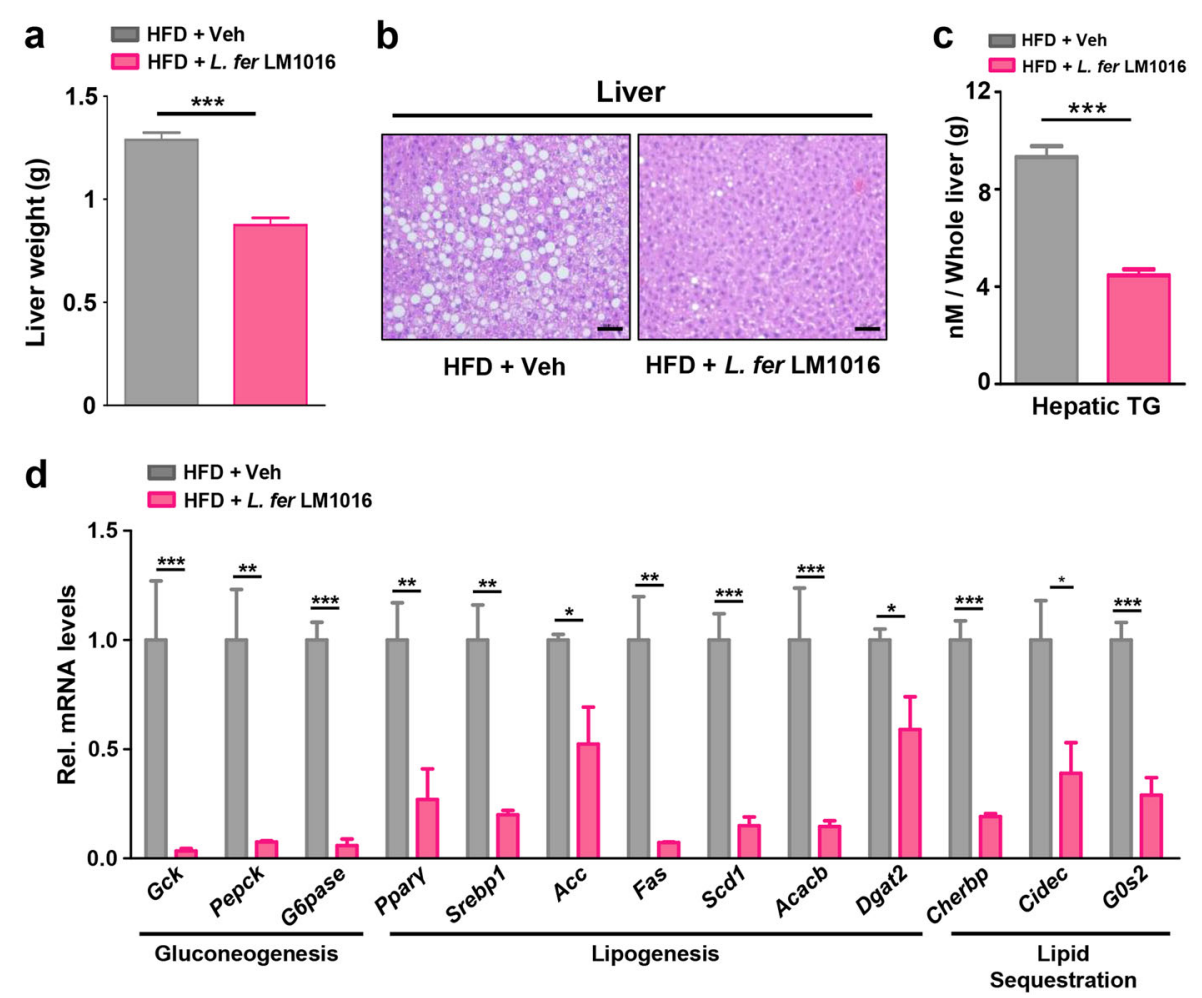

Fig. 4 Administration of $L$. fermentum reduced hepatic gluconeogenesis and lipogenesis to ameliorate hepatic steatosis. a Liver weight. $\mathbf{b}$ Hematoxylin-eosin (H\&E) staining of liver tissues. Scale bar, $100 \mu \mathrm{m}$. c Hepatic triglyceride concentrations. d mRNA expression of gluconeogenesis, lipogenesis, and lipid sequestration genes in the liver. ${ }^{*} p<0.05,{ }^{* *} p<0.01,{ }^{* * *} p<0.001$, as determined by Student's $t$-test (a, $\mathbf{c}$, d). Data are expressed as the means \pm SEMs.

treated with L. fermentum LM1016 compared with those in hepatocytes from HFD-fed mice (Fig. 4d), implying that L. fermentum LM1016 modulated the expression levels of hepatic genes involved in metabolic pathways in the liver to improve liver physiology.

\section{Administration of $L$. fermentum promoted oxidative phosphorylation and attenuated inflammation in adipose tissue}

Consistent with the observed reductions in liver weight, we also found that L. fermentum LM1016 administration reduced the wet weights of inguinal (iWAT) and gonadal WAT (gWAT) (Fig. 5a). Histological analysis of gWAT showed a marked decrease in adipocyte size in mice treated with L. fermentum LM1016 compared with that in HFD-fed mice (Fig. 5b).

Obesity is associated with chronic adipose tissue inflammation, which is characterized by elevation of inflammatory cytokines, such as IL-18, TNF- $\alpha$, and other adipokines released from adipose tissues ${ }^{45,46}$. Therefore, to determine whether the administration of L. fermentum LM1016-attenuated inflammation in adipose tissue, we examined the expression levels of inflammatory cytokine genes by qPCR. The results showed that the expression levels of $F 4 / 80, M c p 1, T G F-\beta, I F N-\gamma, I L-1 \beta$, and $I L-18$ were significantly decreased in gWAT of $L$. fermentum LM1016-treated HFD-fed mice (Fig. 5c). To determine whether systemic inflammation was reduced, we further examined C-reactive protein (CRP), a nonspecific marker of systemic inflammation ${ }^{47,48}$. Consistent with the reduction in inflammation in adipose tissue, we observed that serum CRP levels were markedly reduced by oral treatment with $L$. fermentum LM1016, implying that $L$. fermentum LM1016 treatment largely ameliorated systemic inflammation (Supplementary Fig. S2).

Next, we performed WTS of gWAT to further validate the molecular mechanisms in L. fermentum LM1016treated HFD-fed mice, vehicle-treated HFD-fed mice, and ND-fed mice. GSEA demonstrated that gene sets involved in oxidative phosphorylation were significantly enriched and upregulated in L. fermentum LM1016-treated HFDfed mice and ND-fed mice compared with those in vehicle-treated HFD-fed mice (Fig. $5 \mathrm{~d}$ ). In contrast, gene sets including allograft rejection, TNF- $\alpha$ signaling via nuclear factor (NF) $-\kappa B$, and inflammatory response were significantly downregulated in L. fermentum LM1016treated HFD-fed mice and ND-fed mice, indicating that tissue inflammation was markedly downregulated in 
a
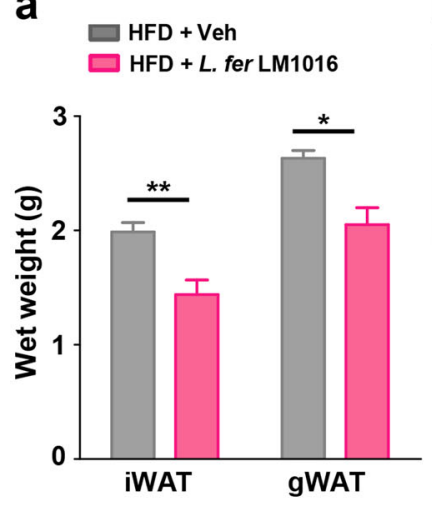

b

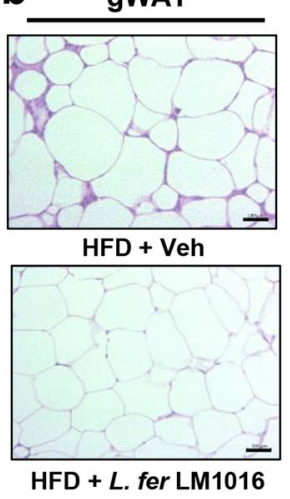

d

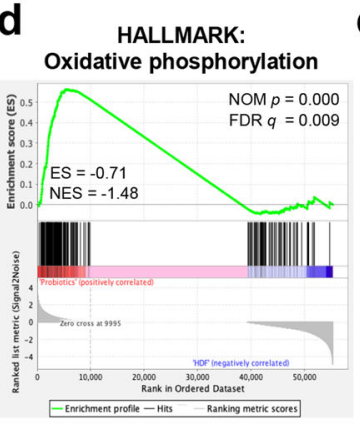

\begin{tabular}{|l|l|l|l}
\hline & & & Atp1ba
\end{tabular}

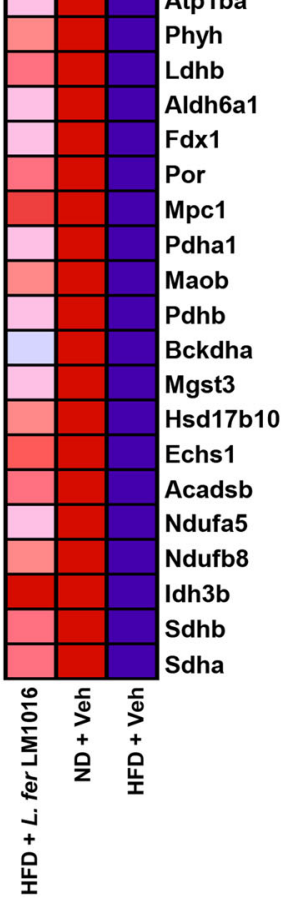

e
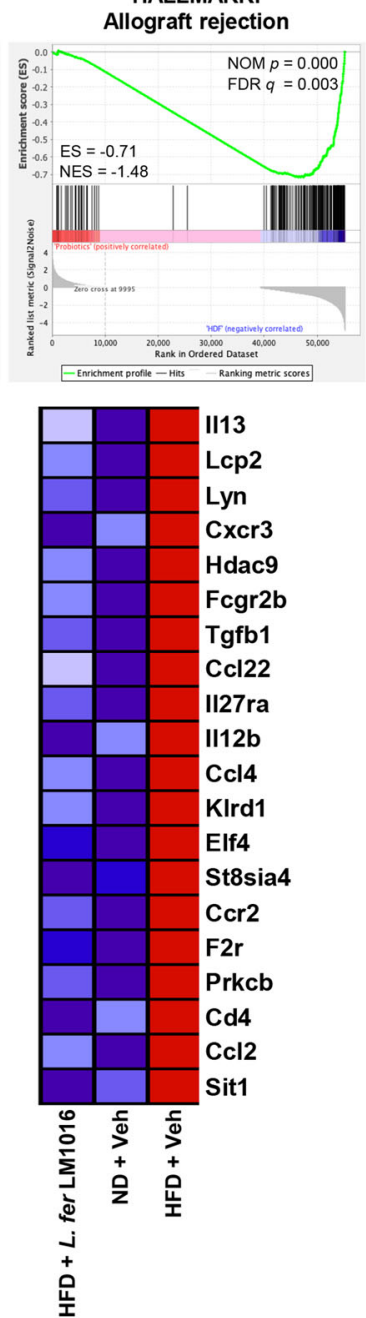

C

$\square$ HFD + Veh

$\square$ HFD + L. fer LM1016

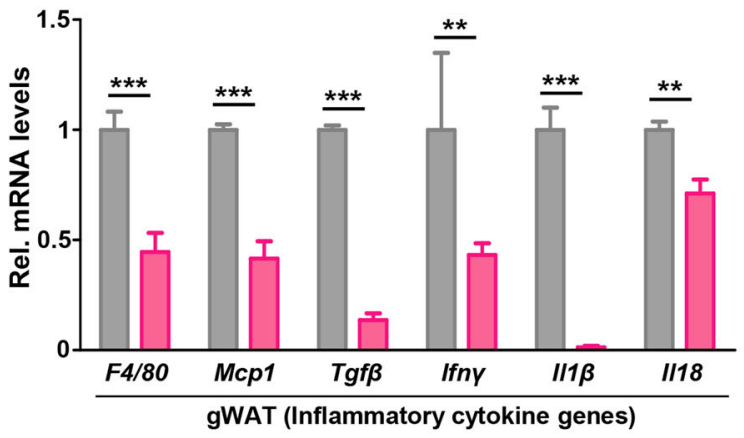

HALLMARK:
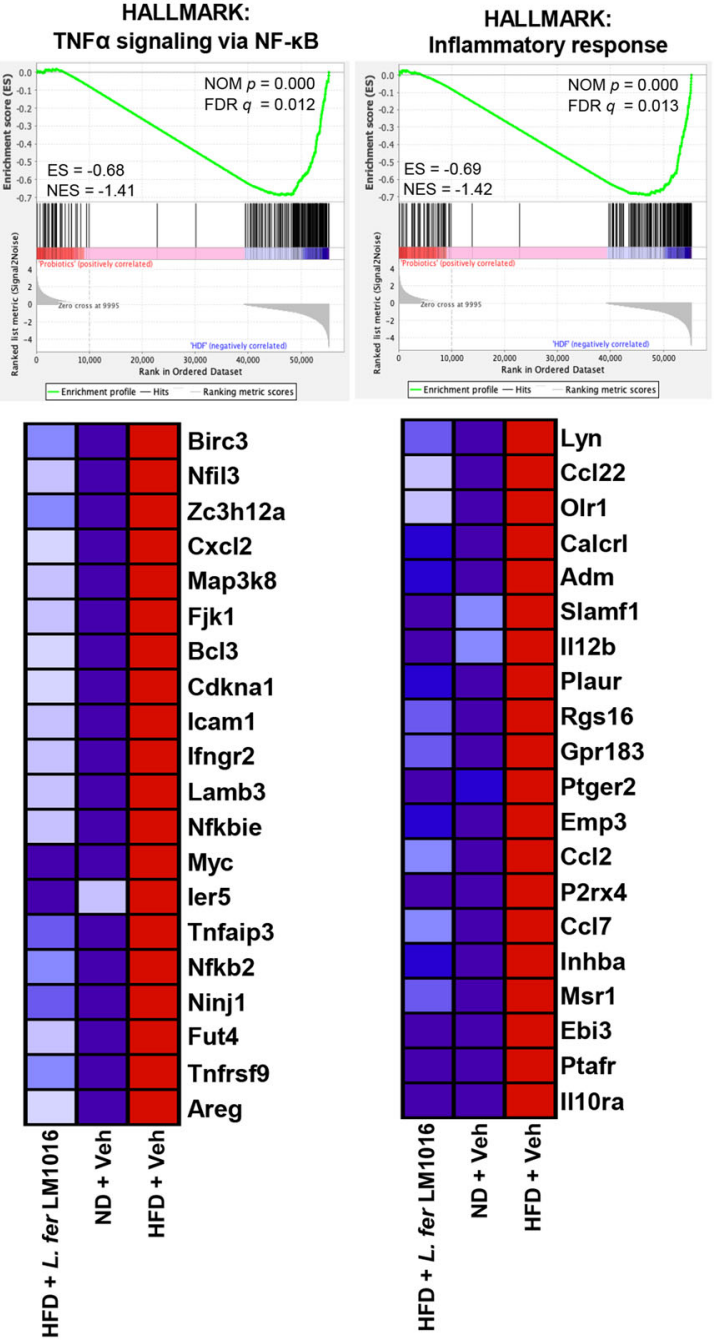

Fig. 5 Administration of $L$. fermentum promoted oxidative phosphorylation and attenuated inflammation in adipose tissue. a Inguinal white adipose tissue (iWAT) and gonadal white adipose tissue (gWAT) weights. b Hematoxylin-eosin (H\&E) staining of gWAT. Scale bar, 100 Hm. c mRNA expression of inflammatory cytokine genes in gWAT. d, e Gene set enrichment analysis (GSEA) of representative significantly enriched hallmark signatures. ES enrichment score, NES net enrichment score, NOM p nominal $p$-value, ${ }^{*} p<0.05,{ }^{* *} p<0.01,{ }^{* * *} p<0.001$, as determined by Student's ttest $(\mathbf{a}, \mathbf{c})$. Data are expressed as means \pm SEMs. 
gonadal adipose tissue by $L$. fermentum LM1016 treatment in HFD-fed mice (Fig. 5e). To determine whether administration of $L$. fermentum LM1016 reduces inflammatory signaling in the intestinal tract, we further performed transcriptome analysis in colonic tissues. Consistent with gWAT transcriptome analysis, GSEA analysis revealed that the expression of genes involved in the inflammatory signaling pathway was markedly reduced by L. fermentum LM1016 administration in HFDfed mice (Supplementary Fig. S3).

\section{Metabolomic profiling of bacterial culture supernatants revealed the anti-obesity metabolites of $L$. fermentum}

To evaluate whether the gut microbiome controlled metabolic tissues, such as the liver and adipose tissue, we hypothesized that metabolites generated from $L$. fermentum LM1016 may have anti-obesity effects to reduce adipogenesis and lipid accumulation. We first tested 3T3L1 preadipocyte differentiation following treatment with bacterial extracts from $L$. fermentum LM1016. Treatment with $L$. fermentum LM1016 bacterial extracts reduced the differentiation of mature adipocytes in 3T3-L1 cell cultures (Fig. 6a, b). Consistent with this, the expression levels of genes involved in adipogenesis, including PPAR $\gamma$, Fas, and adiponectin, were downregulated by treatment with L. fermentum LM1016 bacterial extracts (Fig. 6c).

Previously, plasma levels of LPS were found to be positively correlated with insulin resistance, fasting hyperglycemia, and inflammation in adipose tissue ${ }^{49}$. Thus, we examined the anti-inflammatory effects of $L$. fermentum LM1016 bacterial extracts in LPS-treated 3T3L1 preadipocytes. We treated cells with LPS $(100 \mathrm{ng} / \mathrm{mL})$ and L. fermentum LM1016 bacterial extracts for $24 \mathrm{~h}$ and then carried out enzyme-linked immunosorbent assays (ELISAs) to measure IL-6 in the cell culture medium. The results revealed that IL-6 concentrations were significantly decreased following treatment with LPS and $L$. fermentum LM1016 bacterial extracts compared with concentrations after treatment with LPS only (Fig. 6d).

To identify the metabolites of L. fermentum LM1016 that mediated its anti-obesity effects, we analyzed the metabolites in L. fermentum LM1016 culture supernatants and MRS medium. Metabolomic profiling revealed that 12 metabolites were only present in $L$. fermentum LM1016 culture supernatants and that these metabolites were derived from L. fermentum LM1016 (Table 1). Notably, linoleic acid was only present in $L$. fermentum LM1016 culture media (Table 1). This result reflected the serum metabolomics analysis in which $L$. fermentum LM1016 treatment elevated serum levels of avenoleic acid, a derivative of linoleic acid, in HFD-fed mice (Fig. 3e). To determine whether linoleic acid had anti-obesity properties, we examined the molecular mechanisms of how linoleic acid modulated adipogenesis in 3T3-L1 preadipocytes in vitro. We observed that mature adipocyte differentiation and lipid accumulation were markedly inhibited by linoleic acid treatment (Fig. $6 \mathrm{e}, \mathrm{f}$ ). Moreover, the expression levels of genes involved in adipogenesis, including $S c d 1$ and Srebp1, were also significantly decreased in 3T3-L1 cells treated with linoleic acid (Fig. 6g).

To examine whether both L. fermentum LM1016 bacterial extracts and linoleic acids were able to modulate inflammatory signaling pathways in immune cells, we next determined the gene expression of inflammatory cytokines in RAW 264.7 macrophage cells in the presence or absence of $L$. fermentum LM1016 bacterial extracts and linoleic acid. Consistently, we observed that treatment of L. fermentum LM1016 bacterial extracts and linoleic acid substantially repressed the expression levels of inflammatory cytokine genes, such as IL- $1 \beta$, TNF- $\alpha, \mathrm{F} 4 / 80$, and Mcp1, in RAW 264.7 macrophage cells (Supplementary Fig. S4a). We next measured the protein level of TNF- $\alpha$. Consistently, treatment with both L. fermentum LM1016 bacterial extracts and linoleic acid markedly reduced the protein level of TNF- $\alpha$ secreted by RAW 264.7 macrophage cells (Supplementary Fig. S4b). Similar to RAW 264.7 macrophage cells, we also observed that treatment with both L. fermentum LM1016 bacterial extracts and linoleic acid markedly reduced the expression of inflammatory cytokine genes in 3T3-L1 cells (Supplementary Fig. S5). Altogether, these results demonstrated that $L$. fermentum LM1016 and its metabolites were able to reduce inflammatory signaling pathways in various tissues to protect against diet-induced obesity.

\section{Discussion}

Environmental factors, such as diet, antibiotics, and surgery, are risk factors for dysbiosis and the development of metabolic disorders, including obesity ${ }^{50-53}$. Administration of several Lactobacillus strains has been shown to reduce abdominal adiposity, body weight, and body mass index in animal models and humans ${ }^{20,52,54}$. However, the anti-obesity mechanisms of Lactobacillus strains have not been fully demonstrated at the genetic and metabolomic levels. In this study, we found that administration of $L$. fermentum LM1016 suppressed diet-induced obesity and hepatic steatosis and improved serum metabolic markers, such as glucose, insulin, leptin, and cholesterol. Moreover, GSEA of gWAT revealed that genes involved in oxidative phosphorylation were enriched in gonadal adipose tissue of $L$. fermentum LM1016-treated mice, whereas genes involved in allograft rejection, TNF- $\alpha$ signaling via NF- $\kappa B$, and inflammatory responses were markedly enriched in the gonadal adipose tissue of vehicle-treated mice. Given that obesity-associated metabolic disorders have been shown to correlate with tissue inflammation and oxidative 

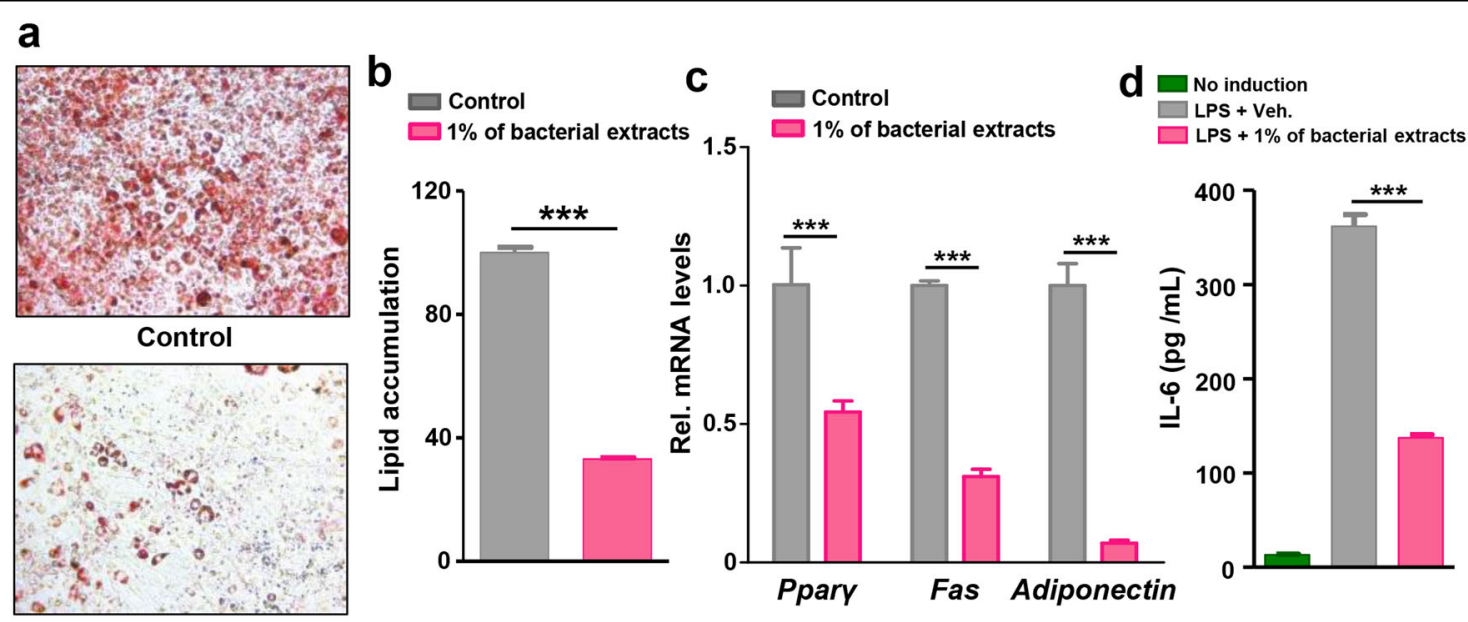

$1 \%$ of bacterial extracts

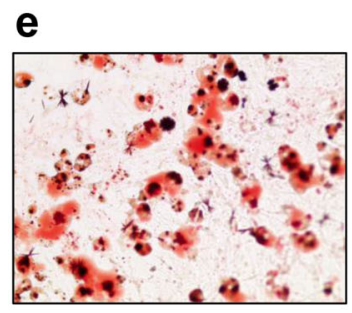
Control
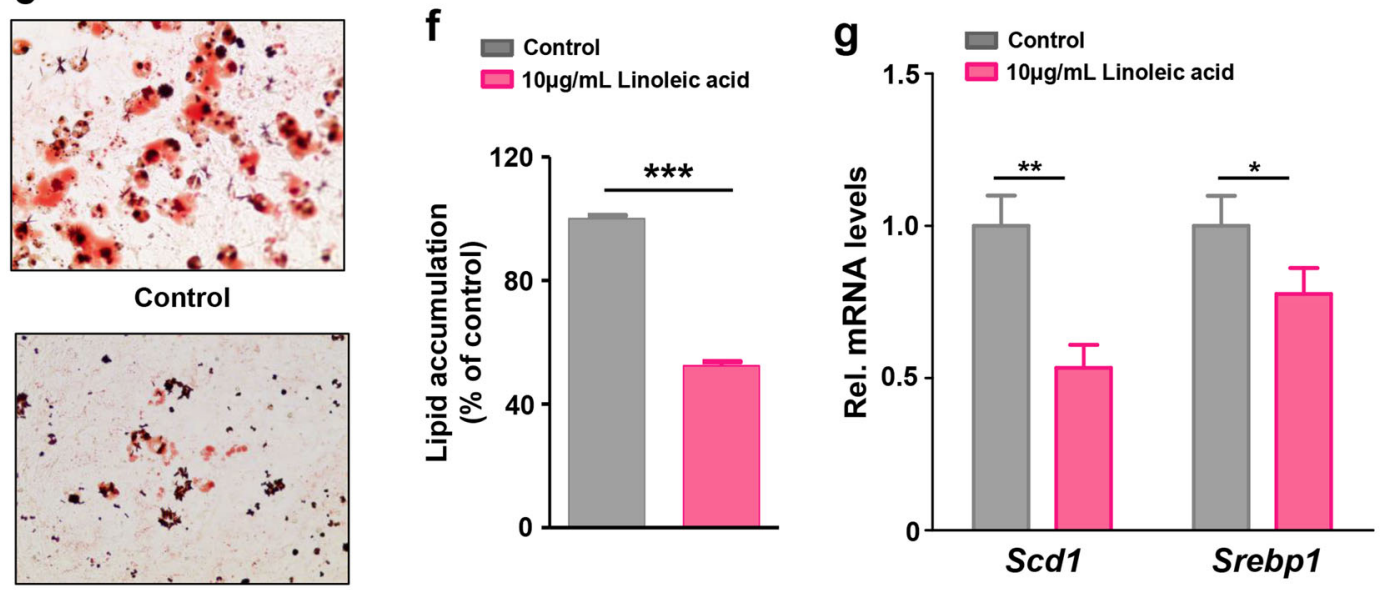

$10 \mu \mathrm{g} / \mathrm{mL}$ Linoleic acid

Fig. 6 L. fermentum LM1016-derived metabolites reduced adipogenesis and inflammation in 3T3-L1 cells. a, b Effects of L. fermentum LM1016 bacterial extraction on 3T3-L1 cell differentiation. Lipid accumulation was determined by Oil Red O staining. c mRNA expression of adipogenesis genes in 3T3-L1 cells treated with or without bacterial extracts. $\mathbf{d}$ IL-6 concentrations in LPS-treated 3T3-L1 cells with or without bacterial extracts. $\mathbf{e}$, $\mathbf{f}$ Effects of linoleic acid on 3T3-L1 cell differentiation. Lipid accumulation was determined by Oil Red O staining. $\mathbf{g}$ mRNA expression of adipogenesis genes in 3T3-L1 cells treated with or without linoleic acid. ${ }^{*} p<0.05,{ }^{* *} p<0.01,{ }^{* * *} p<0.001$, as determined by Student's $t$-test $(\mathbf{b}, \mathbf{c}, \mathbf{f}, \mathbf{g})$ or one-way ANOVA (d). Data are expressed as means \pm SEMs.

stress $^{3,55-57}$, administration of L. fermentum LM1016 may ameliorate oxidative stress and inflammation in WAT.

Bile acid synthesis is a complicated metabolic pathway involving catabolism of cholesterol by numerous hepatic cytochrome P450 enzymes, including CYP7A1 and CYP27A $1^{39,58}$. Farnesoid X receptor (FXR) has been shown to regulate bile acid synthesis, and intestinal FXR activation suppresses bile acid synthesis via mouse FGF15, an ortholog of human FGF1 $9^{40}$. In this study, we showed that administration of L. fermentum LM1016 suppressed the expression of FXR target genes, including FGF15, $I b a b p$, and $O s t \beta$, in the ileum and colon (Fig. 2e, f), leading to induction of hepatic bile acid synthesis. Disruption of the gut microbiota, including reduced bile acid- metabolizing bacteria, markedly impairs bile acid metabolism, leading to dysregulation of host glucose and cholesterol homeostasis and alterations to the immune system $^{59}$. Interestingly, L. rhamnosus GG has been reported to increase intestinal FXR/FGF15 signaling, leading to decreased hepatic bile acid synthesis and prevention of excessive bile acid-induced liver injury and fibrosis in mice ${ }^{60}$. These findings implied that each species of Lactobacillus may have its own physiological functions in regulating intestinal FXR/FGF15 signaling and thereby control hepatic bile acid synthesis in a species-dependent manner.

Using metabolomics analysis, we found that specific metabolites, including linoleic acid, vaccenic acid, and 
Table 1 Comparison of metabolite concentrations between bacterial culture supernatants and control MRS media.

\begin{tabular}{|c|c|c|c|}
\hline & MRS media & $\begin{array}{l}\text { Culture } \\
\text { supernatant }\end{array}$ & $p$-value \\
\hline Vaccenic acid & $0 \pm 0$ & $6.86 \pm 0.03$ & $<0.001$ \\
\hline Linoleic acid & $0 \pm 0$ & $4.85 \pm 0.18$ & $<0.001$ \\
\hline Palmitoleic acid ethyl ester & $0 \pm 0$ & $6.85 \pm 0.03$ & $<0.001$ \\
\hline Oxostearic acid & $0 \pm 0$ & $6.24 \pm 0.03$ & $<0.001$ \\
\hline Chaulmoogric acid & $0 \pm 0$ & $6.14 \pm 0.04$ & $<0.001$ \\
\hline 8,9-Epoxyeicosatrienoic acid & $0 \pm 0$ & $5.57 \pm 0.02$ & $<0.001$ \\
\hline Indolelactic acid & $0 \pm 0$ & $5.80 \pm 0.05$ & $<0.001$ \\
\hline Ethyl pentadecanoate & $0 \pm 0$ & $5.10 \pm 0.10$ & $<0.001$ \\
\hline (R)-2-hydroxystearic acid & $0 \pm 0$ & $7.91 \pm 0.08$ & $<0.001$ \\
\hline $\begin{array}{l}\text { [8-[2-(3-methylbutanoyloxy) } \\
\text { propan-2-yl]-2-oxo-8,9- } \\
\text { dihydrofuro[2,3-h]chromen-9- } \\
\text { yl] (Z)-2-methylbut-2-enoate }\end{array}$ & $0 \pm 0$ & $5.39 \pm 0.06$ & $<0.001$ \\
\hline $\begin{array}{l}\text { 17.alpha.-Hydroxyethyl-5.beta.- } \\
\text { estrane-3.alpha.,17.beta.-diol }\end{array}$ & $0 \pm 0$ & $6.68 \pm 0.06$ & $<0.001$ \\
\hline $\begin{array}{l}\text { [(2S,4As,6R)-3,4'-dihydroxy- } \\
\text { 1,1,4a,6-tetramethyl-6'- } \\
\text { oxospiro[3,4,6,7,8,8a- } \\
\text { hexahydro-2H-naphthalene- } \\
\text { 5,2'-7,8-dihydro-3H-furo[2,3-e] } \\
\text { isoindole]-2-yl] acetate }\end{array}$ & $0 \pm 0$ & $4.29 \pm 0.47$ & 0.004 \\
\hline
\end{tabular}

Normalized $\log 10$

Statistical analysis was determined by Student's $t$-test, Data are expressed as means \pm SEMs.

ethyl pentadecanoate, were only identified in the culture supernatants of $L$. fermentum LM1016. Previous reports showed that supplementation with vaccenic acid reduces serum levels of triglyceride, total cholesterol, and lowdensity lipoprotein (LDL) cholesterol ${ }^{61}$. Additionally, supplementation with conjugated linoleic acid reduced body weight gain and fat accumulation in animals and humans ${ }^{62,63}$. Because these metabolites are secreted or released from the bacterial wall component, these results suggested that administration of L. fermentum LM1016 may increase bacteria-derived specific metabolites in the blood, leading to decreased body weight gain in the HFDfed mouse model. Furthermore, we observed that linoleic acid inhibited adipocyte differentiation and inflammatory responses in 3T3-L1 preadipocytes, suggesting that linoleic acid may be a potent anti-obesity metabolite derived from L. fermentum LM1016.

In summary, we demonstrated that administration of the gut microbe L. fermentum LM1016 ameliorated dietinduced obesity and improved metabolic biomarkers, including glucose, insulin, and leptin. Our results suggest that $L$. fermentum LM1016 treatment may be a potential therapeutic strategy for improving metabolic disorders, such as diet-induced obesity.

\section{Acknowledgements}

We thank CHA Bio Complex for excellent guidance and assistance with the performed mouse experiments. This work was supported by the Bio and Medical Technology Development Program (NRF-2017M3A9F3046536) from the Ministry of Science and ICT, Korean Government, to H.P.; as well as the Bio and Medical Technology Development Program (NRF-2017M3A9F3046538), the Korea Health Technology R\&D Project (HR18C0012) from the Ministry of Health \& Welfare, and the faculty research grant from the Yonsei University College of Medicine (6-2018-0098) to S.F.

\section{Author details}

'Department of Biomedical Science and Engineering, Gwangju Institute of Science and Technology (GIST), Gwangju, Korea. ${ }^{2}$ Genome and Company, Pangyo-ro 255, Bundang-gu, Seoungnam, Korea. ${ }^{3}$ Severance Biomedical Science Institute, BK21 PLUS Project for Medical Science, Gangnam Severance Hospital, Yonsei University College of Medicine, Seoul, Korea

\section{Author contributions}

Y.Y., G.K., S.F., and H.P. designed the experiments; Y.Y., G.K., and J.-h.P. performed the mouse work; Y.Y., G.K., and M.N. performed the cell biology and molecular experiments; G.K. analyzed the GSEA from mouse tissue RNA sequencing; G.K. analyzed ClueGO from bacterial RNA sequencing; M.J. analyzed the mouse and bacterial culture supernatant metabolomics; Y.Y., S.F., and H.P. wrote the manuscript. All authors contributed to the data analysis.

Data availability

The sequencing data reported in this paper were deposited in the European Nucleotide Archive (accession no. ERP120924).

Conflict of interest

The authors declare that they have no conflict of interest.

\section{Publisher's note}

Springer Nature remains neutral with regard to jurisdictional claims in published maps and institutional affiliations.

Supplementary information accompanies this paper at https://doi.org/ 10.1038/s12276-020-00502-w.

Received: 16 April 2020 Revised: 28 June 2020 Accepted: 6 July 2020. Published online: 11 September 2020

\section{References}

1. Chooi, Y. C., Ding, C. \& Magkos, F. The epidemiology of obesity. Metabolism 92 6-10 (2019).

2. Mokdad, A. H. et al. Burden of obesity in the Eastern Mediterranean region: findings from the Global Burden of Disease 2015 study. Int. J. Public Health 63 , 165-176 (2018).

3. Cox, A. J., West, N. P. \& Cripps, A. W. Obesity, inflammation, and the gut microbiota. Lancet Diabet. Endocrinol. 3, 207-215 (2015).

4. Esser, N., Legrand-Poels, S., Piette, J., Scheen, A. J. \& Paquot, N.Inflammation as a link between obesity, metabolic syndrome and type 2 diabetes. Diabet. Res. Clin. Practice 105, 141-150 (2014).

5. Lee, I. S., Shin, G. \& CHoUe, R. Shifts in diet from high fat to high carbohydrate improved levels of adipokines and pro-inflammatory cytokines in mice fed a high-fat diet. Endocr. J. 57, 39-50 (2009).

6. Bastien, M., Poirier, P., Lemieux, I. \& Després, J.P. Overview of epidemiology and contribution of obesity to cardiovascular disease. Prog. Cardiovasc. Dis. 56, 369-381 (2014).

7. Henao-Mejia, J. et al. Inflammasome-mediated dysbiosis regulates progression of NAFLD and obesity. Nature 482, 179 (2012). 
8. Kamada, N., Seo, S.-U., Chen, G. Y. \& Núñez, G. Role of the gut microbiota in immunity and inflammatory disease. Nat. Rev. Immunol. 13, 321 (2013).

9. Claus, S. P., Guillou, H. \& Ellero-Simatos, S. The gut microbiota: a major player in the toxicity of environmental pollutants? Npj Biofilms Microbiomes 2, 16003 (2016).

10. Karasov, W. H., Martinez del Rio, C. \& Caviedes-Vidal, E. Ecological physiology of diet and digestive systems. Ann. Rev. Physiol. 73, 69-93 (2011).

11. LeBlanc, J. G. et al. Bacteria as vitamin suppliers to their host: a gut microbiota perspective. Curr. Opin. Biotechnol. 24, 160-168 (2013).

12. Yatsunenko, T. et al. Human gut microbiome viewed across age and geography. Nature 486, 222 (2012).

13. He, Y. et al. Regional variation limits applications of healthy gut microbiome reference ranges and disease models. Nat. Med. 24, 1532 (2018).

14. Sonnenburg, J. L. \& Bäckhed, F. Diet-microbiota interactions as moderators of human metabolism. Nature 535, 56-64 (2016).

15. Lepage, P. et al. A metagenomic insight into our gut's microbiome. Gut $6 \mathbf{2}$, 146-158 (2013).

16. Paun, A. \& Danska, J. S. Modulation of type 1 and type 2 diabetes risk by the intestinal microbiome. Pediat. Diabet. 17, 469-477 (2016).

17. Bäckhed, F. et al. The gut microbiota as an environmental factor that regulates fat storage. Proc. Natl Acad. Sci. USA 101, 15718-15723 (2004).

18. Ley, R. E. et al. Obesity alters gut microbial ecology. Proc. Natl Acad. Sci. USA 102, 11070-11075 (2005).

19. Lim, S.-M., Jeong, J.-J., Woo, K. H., Han, M. J. \& Kim, D.-H. Lactobacillus sake OK67 ameliorates high-fat diet-induced blood glucose intolerance and obesity in mice by inhibiting gut microbiota lipopolysaccharide production and inducing colon tight junction protein expression. Nutr. Res. 36, 337-348 (2016).

20. Kadooka, Y. et al. Effect of Lactobacillus gasseri SBT2055 in fermented milk on abdominal adiposity in adults in a randomised controlled trial. Br. J. Nutr. 110, 1696-1703 (2013).

21. Ji, Y. et al. Amelioration of obesity-related biomarkers by Lactobacillus sake CJLS03 in a high-fat diet-induced obese murine model. Sci. Rep. 9, 6821 (2019).

22. Ji, Y. et al. Modulation of the murine microbiome with a concomitant antiobesity effect by Lactobacillus rhamnosus GG and Lactobacillus sakei NR28. Benef. Microbes 3, 13-22 (2012)

23. Schwendimann, L., Kauf, P., Fieseler, L., Gantenbein-Demarchi, C. \& Schwenninger, S. M. Development of a quantitative PCR assay for rapid detection of Lactobacillus plantarum and Lactobacillus fermentum in cocoa bean fermentation. J. Microbiol. Methods 115, 94-99 (2015).

24. Hill, D. A. et al. Metagenomic analyses reveal antibiotic-induced temporal and spatial changes in intestinal microbiota with associated alterations in immune cell homeostasis. Mucosal Immunol. 3, 148-158 (2010).

25. Dobin, A. et al. STAR: ultrafast universal RNA-seq aligner. Bioinformatics 29 15-21 (2013)

26. Li, B. \& Dewey, C. N. RSEM: accurate transcript quantification from RNA-Seq data with or without a reference genome. BMC Bioinformatics 12, 323 (2011).

27. Mootha, V. K. et al. PGC-1a-responsive genes involved in oxidative phosphorylation are coordinately downregulated in human diabetes. Nat. Genet. 34, 267 (2003).

28. Subramanian, A. et al. Gene set enrichment analysis: a knowledge-based approach for interpreting genome-wide expression profiles. Proc. Natl Acad. Sci. USA 102, 15545-15550 (2005).

29. Trapnell, C. et al. Differential gene and transcript expression analysis of RNAseq experiments with TopHat and Cufflinks. Nat. Protoc. 7, 562-578 (2012).

30. Bindea, G. et al. ClueGO: a Cytoscape plug-in to decipher functionally grouped gene ontology and pathway annotation networks. Bioinformatics $\mathbf{2 5}$ 1091-1093 (2009).

31. Furukawa, S. et al. Increased oxidative stress in obesity and its impact on metabolic syndrome. J. Clin. Investig. 114, 1752-1761 (2017).

32. Lee, H., Lee, Y. J., Choi, H., Ko, E. H. \& Kim, J.-W. Reactive oxygen species facilitate adipocyte differentiation by accelerating mitotic clonal expansion. J. Biol. Chem. 284, 10601-10609 (2009).

33. Serra, D., Mera, P., Malandrino, M. I., Mir, J. F. \& Herrero, L. Mitochondrial fatty acid oxidation in obesity. Antioxid. Redox Signal. 19, 269-284 (2013).

34. Savini, I., Catani, M. V., Evangelista, D., Gasperi, V. \& Avigliano, L. Obesityassociated oxidative stress: strategies finalized to improve redox state. Int. J. Mol. Sci. 14, 10497-10538 (2013).

35. Cypess, A. M. et al. Identification and importance of brown adipose tissue in adult humans. N. Engl. J. Med. 360, 1509-1517 (2009).
36. Lowell, B. B. et al. Development of obesity in transgenic mice after genetic ablation of brown adipose tissue. Nature 366, 740-742 (1993).

37. Yoneshiro, T. \& Saito, M. Activation and recruitment of brown adipose tissue as anti-obesity regimens in humans. Ann. Med. 47, 133-141 (2015).

38. Watanabe, $\mathbf{M}$. et al. Bile acids induce energy expenditure by promoting intracellular thyroid hormone activation. Nature 439, 484-489 (2006).

39. Chiang, J. Y. Bile acids: regulation of synthesis. J. Lipid Res. 50, 1955-1966 (2009).

40. Inagaki, T. et al. Fibroblast growth factor 15 functions as an enterohepatic signal to regulate bile acid homeostasis. Cell Metab. 2, 217-225 (2005).

41. Brestoff, J. R. \& Artis, D. Commensal bacteria at the interface of host metabolism and the immune system. Nat. Immunol. 14, 676-684 (2013).

42. Lewis-Barned, N. et al. Plasma cholesteryl ester fatty acid composition, insulin sensitivity, the menopause and hormone replacement therapy. J. Endocrinol. 165, 649-655 (2000).

43. Koppe, S. W. Obesity and the liver: nonalcoholic fatty liver disease. Transl. Res. 164, 312-322 (2014).

44. Kim, C.-S. et al. Quercetin reduces obesity-induced hepatosteatosis by enhancing mitochondrial oxidative metabolism via heme oxygenase-1. Nutr. Metab. 12, 33 (2015).

45. Fantuzzi, G. Adipose tissue, adipokines, and inflammation. J. Allergy Clin. Immunol. 115, 911-919 (2005)

46. Tilg, H. \& Moschen, A. R. Adipocytokines: mediators linking adipose tissue, inflammation and immunity. Nat. Rev. Immunol. 6, 772-783 (2006).

47. Ridker, P. M., Hennekens, C. H., Buring, J. E. \& Rifai, N. C-reactive protein and other markers of inflammation in the prediction of cardiovascular disease in women. N. Engl. J. Med. 342, 836-843 (2000).

48. Marnell, L., Mold, C. \& Du Clos, T. W. C-reactive protein: ligands, receptors and role in inflammation. Clin. Immunol. 117, 104-111 (2005).

49. Cani, P. D. et al. Metabolic endotoxemia initiates obesity and insulin resistance Diabetes 56, 1761-1772 (2007).

50. Graessler, J. et al. Metagenomic sequencing of the human gut microbiome before and after bariatric surgery in obese patients with type 2 diabetes: correlation with inflammatory and metabolic parameters. Pharmacogenomics J. 13, 514-522 (2013).

51. Liu, R. et al. Gut microbiome and serum metabolome alterations in obesity and after weight-loss intervention. Nat. Med. 23, 859 (2017).

52. Kadooka, Y. et al. Regulation of abdominal adiposity by probiotics (Lactobacillus gasseri SBT2055) in adults with obese tendencies in a randomized controlled trial. Eur. J. Clin. Nutr. 64, 636-643 (2010).

53. Bailey, L. C. et al. Association of antibiotics in infancy with early childhood obesity. JAMA Pediatr. 168, 1063-1069 (2014).

54. Ji, Y. et al. Amelioration of obesity-related biomarkers by Lactobacillus sake CJLS03 in a high-fat diet-induced obese murine model. Sci. Rep. 9, 1-11 (2019).

55. Zeyda, M. \& Stulnig, T. M. Obesity, inflammation, and insulin resistance: a minireview. Gerontology 55, 379-386 (2009).

56. Galinier, A. et al. Adipose tissue proadipogenic redox changes in obesity. J. Biol. Chem. 281, 12682-12687 (2006).

57. Lechuga-Sancho, A. M. et al. Obesity induced alterations in redox homeostasis and oxidative stress are present from an early age. PLOS ONE 13, e0191547 (2018).

58. Russell, D. W. The enzymes, regulation, and genetics of bile acid synthesis. Ann Rev. Biochem. 72, 137-174 (2003).

59. Chávez-Talavera, O., Tailleux, A., Lefebvre, P. \& Staels, B. Bile acid control of metabolism and inflammation in obesity, type 2 diabetes, dyslipidemia, and nonalcoholic fatty liver disease. Gastroenterology 152, 1679-1694 (2017). e1673.

60. Liu, Y. et al. Probiotic LGG prevents liver fibrosis through inhibiting hepatic bile acid synthesis and enhancing bile acid excretion in mice. Hepatology 71, 2050-2066 (2019)

61. Wang, Y. et al. Trans-11 vaccenic acid dietary supplementation induces hypolipidemic effects in JCR: LA-cp rats. J. Nutr. 138, 2117-2122 (2008).

62. Jacome-Sosa, M. M. et al. Increased hypolipidemic benefits of cis-9, trans-11 conjugated linoleic acid in combination with trans-11 vaccenic acid in a rodent model of the metabolic syndrome, the JCR: LA-cp rat. Nutr. Metab. 7, 60 (2010).

63. Pariza, M. W., Park, Y. \& Cook, M. E. Conjugated linoleic acid and the control of cancer and obesity. Toxicol. Sci. 52, 107-110 (1999). 